\title{
"UM ESPECTRO RONDA O RIO DE JANEIRO": MODERNISMO SOVIÉTICO, A NOVA FRANKFURT E A OBRA DE ALTBERG NO BRASIL
}

\author{
Liszt Vianna Neto ${ }^{1}$
}

DOI: 10.5752/P.2316-1752.2017v25n36p104

\begin{abstract}
Resumo
O presente artigo aborda a trajetória de Alexander Altberg, arquiteto berlinense imigrado para o Rio de Janeiro em 1931 e ex-aluno da Bauhaus e do proeminente arquiteto Arthur Korn. No Brasil, Altberg atuou não apenas como arquiteto e principal realizador da vanguardista revista Base, mas também como um importante representante do modernismo alemão. Como muitos imigrantes alemães da década de 1930, teve o exercício da profissão vetado pelo governo Vargas e sua trajetória esquecida, como muitos dos primeiros arquitetos modernos.
\end{abstract}

Palavras-chave: História da arquitetura. Modernismo brasileiro. Imigração alemã.

\footnotetext{
1. Doutorando pela Universidade de Leiden, Países Baixos. Bolsista CAPES de doutorado pleno (processo n. BEX 1225/15-4). Mestre em Arquitetura e Urbanismo pela UFMG. Mestre em História pela UFMG. Email: lisztvianna@gmail.com
} 
"A SPECTRE IS HAUNTING RIO DE JANEIRO": SOVIET MODERNISM, NEW FRANKFURT AND THE WORK OF ALTBERG IN BRAZIL
"UN ESPECTRO SE CIERNE SOBRE RIO DE JANEIRO": MODERNISMO SOVIÉTICO, NUEVO FRANKFURT Y LA OBRA DE ALTBERG EN BRAZIL

\section{Resumen}

El presente artículo aborda la trayectoria de Alexander Altberg, arquitecto berlinés inmigrado para Río de Janeiro en 1931, ex alumno de la Bauhaus y del prominente arquitecto Arthur Korn. En Brasil, Altberg actuó no sólo como arquitecto y principal realizador de la vanguardista revista Base, sino también como un importante representante del modernismo alemán. Como muchos inmigrantes alemanes de la década de 1930, tuvo el ejercicio de la profesión vetado por el gobierno Vargas y su trayectoria olvidad, como muchos de los primeros arquitectos modernos.

Palabras-claves: História de la Arquitectura. Modernismo brasileño. Imigracíon alemana.
Keywords: History of architecture. Brazilian modernism. German immigration. 
Como é praxe no meio acadêmico, o título deste artigo contém uma provocação. No entanto, o artifício retórico não invalida a questão: Haveria no Brasil algum vestígio do modernismo arquitetônico soviético? A historiografia da arquitetura não cita nenhum arquiteto, formado no seio da Revolução de 1917, que seja mesmo vagamente relacionado ao modernismo brasileiro. Gregori Warchavchik, predecessor do modernismo no Brasil, nasceu em Odessa, Império Russo à época, mas se formou em Roma - e não se sabe que tenha tido qualquer contato com as vanguardas russas pós-revolucionárias.

Sabe-se, porém, que um arquiteto berlinense, comunista e ex-aluno da Bauhaus imigrou para o Brasil em 1931. Antes disso, Alexander Altberg encontrava-se no entroncamento de três matrizes alemãs em contato direto com as experiências arquitetônicas soviéticas. Seu primeiro emprego como arquiteto, no escritório de Arthur Korn, o colocou no centro do debate acerca da arquitetura proletária desenvolvido em Berlim, a partir das experiências de Hannes Meyer, diretor da Bauhaus, e Ernst May, que palestrava em Berlin sobre suas experiências em Magnitogorski e na Nova Frankfurt.

Contudo, a radicalidade do ideário político de Altberg precedia em muito sua experiência no Coletivo para a Arquitetura Socialista, fundado por Arthur Korn. Seus pais eram francamente comunistas, e as memórias da mais tenra infância 
de Altberg são os jornais "Bandeira Vermelha" à porta de casa e o distanciamento da família da religiosidade judaica do entorno. Sua mãe, além de lhe ensinar sua língua nativa, o russo, levava o jovem Alexander para assistir a discursos de Rosa Luxemburgo em praças públicas. Isso o impeliu desde muito cedo a se engajar na criação de célula do Partido Comunista Alemão no bairro de Wilmersdorf².

A contrassenso das expectativas, o breve período de Altberg na Bauhaus foi muito pouco ativo politicamente. A escola sabidamente recebia alunos estrangeiros e nacionais, que se organizavam em grupos e clubes, entre eles, coletivos de variados espectros socialistas. Havia até mesmo, entre os professores, diversos matizes de tal pensamento, como é exemplo o socialismo difuso de Walter Gropius, ou o engajamento estritamente partidário de Hannes Meyer. Apesar disso, Altberg cumpriu apenas os cursos preliminares da escola - sendo impelido pelas dificuldades econômicas a buscar uma formação menos generalista e mais estritamente arquitetônica - e por isso oposta às propostas da Bauhaus.

O ideário político de Altberg só encontrou verdadeiro respaldo em sua primeira prática profissional, empregado no escritório Korn \& Weitzmann. Se Weitzmann parece ter 
sido a mente empresarial do escritório, Arthur Korn deu vazão a todas as ambições de Altberg em atrelar seu engajamento político à radicalidade do movimento moderno. A atividade político-arquitetônica de Korn como fundador do Coletivo para Arquitetura Socialista foi, no entanto, precedida por uma longa trajetória. Inicialmente engajado na causa sionista, onipresente nos círculos judaicos da República de Weimar, Korn aproximou-se posteriormente das principais associações de arquitetos de matriz socialista: primeiramente o Novembergruppe, em 1922, em seguida o Ring, em 1926 - onde palestrou junto Hugo Häring, Walter Gropius e Bruno Taut sobre urbanismo -, finalmente aderindo ao CIAM (Congresso Internacional de Arquitetura Moderna), em 1932. Ao lecionar na Escola de Trabalhadores Marxistas (MARSCH), entre 1930 e 1931, acumularia valiosa experiência para formar o Coletivo de Arquitetura Socialista, que amalgamava estudantes do "Clube Vermelho" da Universidade Técnica de Berlim e da Bauhaus em Dessau³.

O período de Altberg no escritório entre 1928 e 1931 coincide justamente com a inflexão da vida profissional de Korn: deixando de ser um arquiteto de luxuosas mansões da burguesia mercantil judaica berlinense, tornando-se um urbanista interessado nos aspectos históricos das cidades e na

3. KORN Arthur; FRY, Maxwell; SHARP, Dennis. The M.A.R.S. Plan for London. Perspecta, Vol. 13, 1971. 
solução de suas contradições a partir de uma perspectiva dialética materialista. É nesse período que Korn percorre várias cidades da União Soviética - Moscou, Baku, Batumi, Tashkent, Tbilisie - e conhece pessoalmente figuras proeminentes do campo arquitetônico soviético, como Mosei Ginsburg, Alexander Wesnin e o próprio Ernst May.

Entretanto, quando se trata das influências das matrizes socialistas da Bauhaus, da chamada "Brigada May" e de Arthur Korn sobre Altberg, não se pode deixar de ter em mente as profundas cisões entre essas três vertentes.

Em 1927, arquitetos russos do grupo VOPRA visitaram a Bauhaus em Dessau, tendo contato com discentes e docentes, em especial com o futuro diretor da escola, Hannes Meyer. Posteriormente, Hannes Meyer retribuiria a visita organizando uma exposição da Bauhaus em Moscou. Quando Meyer, filiado ao partido comunista, imigrou brevemente para a URSS, em 1930, se uniu imediatamente a VOPRA, junto com mais sete de seus ex-alunos da Bauhaus ${ }^{4}$.

Ao retornar a Berlim, enquanto ocorria a Exposição de Arquitetura Proletária, organizada por Altberg e o Coletivo, Meyer participa junto a Korn na organização do CIAM em Moscou, como representante do VOPRA. A cisão entre as

4. GORELIK, Adrian; LIERNUR, Jorge Francisco. La sombra de la vanguardia: Hannes Meyer en Mexico, 1938-1949. Buenos Aires: Proyecto, 1993. 
concepções acerca do que era "arquitetura proletária", no entanto, divergiam amplamente entre Meyer e Korn. O Coletivo baseara seus planos de uma "cidade linear" alemã no projeto de Sotsgorod de Nicolaj Miljutin, que, mais do que conhecido como um expoente da arquitetura proletária soviética, era denunciado pelo VOPRA como um elemento do vanguardismo burguês do passado.

Desde sua fundação em 1929, o VOPRA era composto por estudantes de arquitetura formados dentro do escopo da VKhUTEMAS, mas radicalmente opostos aos velhos mestres e às vertentes vanguardistas autodenominadas construtivistas, formalistas ou racionalistas. Com a dissolução da VkhUTEMAS em 1930, o ASI, Instituto de Arquitetura, capitaneou justamente a "revolução cultural" defendida pelos antigos alunos, incluindo os membros do VOPRA.

Korn também nutria uma relação ambígua com Ernst May. Se por um lado ele denunciava que "o front que se estende de (Ersnt) May a Le Corbusier (deve enfrentar) a oposição de um forte front marxista"; por outro, segundo Siegfried Kracauer, pouco diferenciava-se a Exposição de Arquitetura Proletária de Korn das palestras de Ernst May em Berlim, a respeito de suas experiências em Magnitogorski e na Nova Frankfurt. Korn possuía uma perspectiva francamente utópica em relação ao planejamento urbano - visando à coletivização radical das habitações. Ernst May, tendo de lidar com 
problemas de ordem absolutamente pragmática, optou por soluções de compromisso em Frankfurt. Até mesmo os arquitetos soviéticos já haviam abandonado a coletivização radical da habitação social à época. A URSS havia apontado May como chefe de planejamento das novas cidades pelo NDKTP (Comissariado Popular da Indústria Pesada) justamente para evitar a guinada radical a esquerda empreendida por Hannes Meyer e o VOPRA. Meyer denunciava o formalismo de May e Le Corbusier, por compreender que o problema da habitação social não era de ordem técnica ou projetual, mas uma questão política, do proletariado e do modo de produção. Korn concordaria, respaldado pela questão da habitação em Engels, e seus planos para Berlim, como a Magnitogorski de Ivan Leonidov, a Stalingrado de Vladmir Semenov, e a Sotsgorod de Nicolaj Miljutin, só seriam levados a cabo após uma revolução socialista alemã. Em discurso na Exposição de Arquitetura Proletária, Kurt Meyer também se oporia a May, ao apresentar seu modelo concêntrico para as intervenções em Moscou, oposto ao modelo satelital de May. Tais ambiguidades se dissolvem, se se levar em conta que, apesar das divergências nas minúcias quanto ao papel da arquitetura na revolução, Korn, Meyer e May eram unidos pela interpretação materialista da sociedade, pela leitura marxista da questão da habitação proletária e pelas práticas coletivistas e horizontais no que tange o projeto arquitetônico - ainda que com graves distorções entre o discurso e a praxe. 
Já a Exposição de Arquitetura Proletária, propriamente dita, encontrava-se em incrível afinidade com os debates desenvolvidos pelo CIAM e por Ernst May. O sistema urbanístico que Korn organizou com Peter Friedrich para Berlim fora inspirado nos grandes centros produtores de aço nos EUA: Indiana e Pittsburgh, Pensilvânia. Como mostrado nos cartazes da Exposição, o projeto para Magnitogorsk seguia um desenho de "cidade linear", uma inovação do urbanismo soviético de Milyutin, com corredores separando superblocos habitacionais paralelos às fábricas e um cinturão verde separando ambas as áreas. Os projetos alinhavam o setor de moradia e produção para reduzir o tempo de viagem entre ambos e, assim, os trabalhadores habitariam a linha paralela ao setor industrial em que trabalhavam. A realidade russa, no entanto, diferia muito dos projetos apresentados na Exposição. A "Brigada May", atraída pelo cenário de tábula rasa de Magnitogorski, se surpreendeu ao chegar à cidade e encontrar a zona industrial e algumas das habitações já construídas. May teve que abandonar o projeto original de superblocos lineares para adequá-los às curvas do rio na margem oposta à indústria, como fizera em Frankfurt, o que por sua vez aumentou o tempo de viagem dos operários. May também teve que lidar com as autoridades soviéticas, com os atrasos, com a corrupção, com o inverno, etc ${ }^{5}$. 
Obviamente, o conteúdo soviético da Exposição chamou atenção indesejada. Altberg, secretário do coletivo, enfatizava os riscos reais que os integrantes corriam na Exposição de Arquitetura Proletária:

A exposição de arquitetura proletária, como nós dizemos, era uma necessidade devido à falta de moradias para gente pobre na cidade de Berlim, como em outros lugares também. Para angariar financiamento, o Korn deu a idéia de fazer essa exposição e eu naturalmente estava de acordo. Nós conseguimos a locação de um do que hoje se chama de apartamento, uma moradia. O apartamento era um buraco e nós fizemos por conta própria a exposição, que chamou a atenção do governo. Tanto assim que em uma das propagandas que nós mandamos para os jornais de Berlim para serem publicadas estava meu nome como secretário desse coletivo de construção. [...] Acontece que alguns dias depois apareceu, nesse quarto alugado, no oeste de Berlim, [...] um camarada que de longe se 'cheirava' que era polícia. E ele me disse que ele era tratorista. Trabalhava com trator e precisava de trabalho, se podia trabalhar na obra. E eu, com dificuldade, tive que explicar a ele que por enquanto isso tudo é projeto, quando tivermos construindo ele podia se reapresentar para ser tratorista. (ALTBERG, Alexander. Memórias. Não publicado)

Por seu conteúdo incendiário, a Exposição foi alvo de muitas suspeitas. E o risco era real: posteriormente dois membros do coletivo foram presos por suas ações antifascistas, sendo um deles assassinado e outro enviado a um campo 
de concentração .

A imprensa, por outro lado, foi o mais das vezes silente. Quando se manifestava, era agente de grandes escândalos: Hannes Meyer perdeu a direção da Bauhaus, impelido pela opinião pública, enquanto Ernst May era chamado pelos jornais de "Lênin da construção", por utilizar blocos pré-fabricados em Frankfurt - chamada de "pequena indústria soviética".

May também inflamou a imprensa, ao tratar do urbanismo soviético, quando convidado pelo CIAM como palestrante. Seu discurso se opunha à Exposição Alemã, simultânea à de Arquitetura Proletária. O jornal social-democrata "Avante" se referiu tanto à Exposição de Arquitetura Proletária quanto aos projetos de May em Frankfurt como uma "homogeneidade sem alma", apelidando-os de "corseletes de ferro" e descrevendo seus moradores como "escravos estatais imprensados juntos"7. O programa da Exposição era constituído de três elementos fundamentais: habitação, urbanismo e tráfego. Desses três elementos, a maior parte é dedicada à habitação.

Opondo-se ao diagnóstico do Coletivo sobre os problemas da habitação na Alemanha - o déficit habitacional, a insalu- 
bridade, a flamabilidade, os altos aluguéis, etc. -, apresenta-se a solução da URSS para o problema. A solução soviética é colocada de forma notadamente esperançosa, quase utópica. O coletivo busca ir além da habitação unifamiliar de existência mínima, como em muitas críticas de arquitetos alemães funcionalistas, incluindo a arquitetura frankfurtiana de May e a casa-modelo da Bauhaus. Para isso, a coletivização dos afazeres domésticos era fundamental. Tal análise dos projetos soviéticos se estendeu à interpretação de Berlim, em um projeto de Korn e dos membros do coletivo. "Die Stadt als Hotel und Fabrik" (A cidade como hotel e fábrica) antevê uma Berlim futura em uma Alemanha soviética que lida com "os problemas da habitação individual até a região de Berlim". Seria uma "cidade para uma sociedade livre de classes", livre da propriedade privada do solo, das terras, dos meios de produção e das construções ${ }^{8}$.

O nome "A cidade como hotel e fábrica" se refere às duas funções principais da cidade, habitação e trabalho, que deveriam ser conectadas pelo transporte e preenchidas pelas recreações. Seria uma Berlim "elástica", projetada sob os princípios da racionalidade, da facilidade de locomoção, circundada bilateralmente por áreas verdes. O projeto seguia

8. ZEESE, Andreas. Die vergessene Moderne: Arthur Korn - Architekt, Urbanist, Lehrer (1891-1978). Leben und Werk eines jüdischen Avantgardisten in Berlin und London. Tese defendida pela Universidade de Viena, 2010. p.184. 
o conceito de "cidade linear", ou Bandstadt (cidade em fita) de Milyutin, que visava eliminar a dicotomia cidade-campo. ${ }^{9}$

$\mathrm{Na}$ visada francamente utópica do Coletivo, a cidade de Berlim seria parcialmente demolida e, reintegrada à "cidade linear", se estenderia até Potsdam, orientada no sentido Sudoeste-Nordeste. A densidade populacional seria extrema, e a cidade constituída por prédios paralelos em altura, tendo entre os blocos uso como jardins e hortas, de construção estrutural estandartizada, com pilotis livre, formando cada bloco uma comunidade com muitos serviços autônomos e autogeridos. A cidade seria dividida em três funções. Uma "coluna-espinhal" seria "faixa da cultura", que ocuparia ambos os lados da avenida central, onde se localizariam estabelecimentos culturais, administrativos e técnicos ${ }^{10}$. Já o trânsito seria reduzido pelo espaço estreito entre a faixa habitacional e a produtiva, que, como em Magnitogorsk, eram consideravelmente próximas.

Aparte casos excepcionais, os trabalhadores soviéticos simplesmente não se adaptaram à vida comunal imposta e às habitações dormitórios. Deve-se lembrar que os trabaIhadores urbanos soviéticos eram, há pouco mais de uma

9. CATÁLOGO DA EXPOSIÇÃO DE ARQUITETURA PROLETÁRIA. Berlim: 1931.

10. ZEESE, Andreas. Die vergessene Moderne: Arthur Korn - Architekt, Urbanist, Lehrer (1891-1978). Leben und Werk eines jüdischen Avantgardisten in Berlin und London. Tese defendida pela Universidade de Viena, 2010. 
década, trabalhadores rurais sob um regime feudal - e que agora habitavam comunas pós-capitalistas.

Evidentemente, o projeto dessas novas habitações comunais foi totalmente abandonado - sobretudo após o início da Segunda Guerra Mundial. Implantou-se um modelo híbrido, prevendo não apenas habitações individuais, mas também a vida em família, contando até com uma pequena cozinha em um nicho na parede. Contudo, o que efetivamente se aplicou por toda União Soviética nas décadas do pós-Segunda Guerra foi o que na Alemanha Oriental se chamou de Plattenbau - construções em módulos completamente pré-fabricados, em blocos maciços de apartamentos que mais se assemelhavam a um "lar burguês" em miniatura do que aos condensadores sociais sonhados pela vanguarda construtivista.

O experimentalismo soviético, entretanto, foi acompanhado de algumas conquistas sociais consideráveis. Uma delas é a libertação feminina - firmemente defendida pelos projetos de May e Korn. Desde os primeiros anos da revolução, às mulheres foram garantidos direitos que a maioria dos países desenvolvidos europeus conquistaria muitas décadas depois: direitos trabalhistas iguais entre homens e mulheres, direito ao aborto, ao divórcio, etc. Se por um lado as mulheres passaram a ter mais direitos, por outro, sua entrada no mundo do trabalho não doméstico pratica- 
mente dobrou a mão-de-obra disponível em poucos anos. A outra conquista foi o atendimento efetivo à demanda habitacional, de maneira rápida e barata, por meio do sistema de pré-fabricação - mesmo que não seguindo o modelo almejado pelos arquitetos e com qualidade crescentemente limitada.

\section{"Um espectro ronda o Rio de Janeiro"}

Para além do ideário político e da concepção urbanística, a revista Neue Frankfurt, editada por May, parece ter impactado dramaticamente na visão estética de Altberg. O exemplo mais claro dessa influência é a Revista Base, criada e levada adiante por Altberg. Como a Bauhaus, definida programaticamente como escola de arte e técnica, a revista Base se definia como revista de "arte, técnica e pensamento" e abrangia em seu programa "arquitetura, pintura e escultura, literatura, música, teatro, foto e cinematografia, dansa (sic), reclame e tipografia, educação e higiene, urbanismo e tráfego". Em artigo da revista, Altberg afirma que: "A 'Base' não quer nem pretende ser uma revista do gênero para divertir, mas sim uma coletividade, um núcleo de trabalhadores que, mui (sic) seriamente se ocupa com todos os problemas da arte, da técnica e do pensamento Uma visada superficial da Base já indica sua filiação com a Neue Frankfurt (figuras 1 e 2). Ambas possuem uma organização gráfica estritamente ortogonal, sendo impressas 
em preto, branco e uma cor primária. A tipografia não serifada deixa claro o distanciamento de qualquer forma de historicismo, enquanto a indiferenciação entre maiúsculas e minúscula propõe uma organização não-hierarquizada do texto - o que por sua vez tem uma conotação simbólica importante.

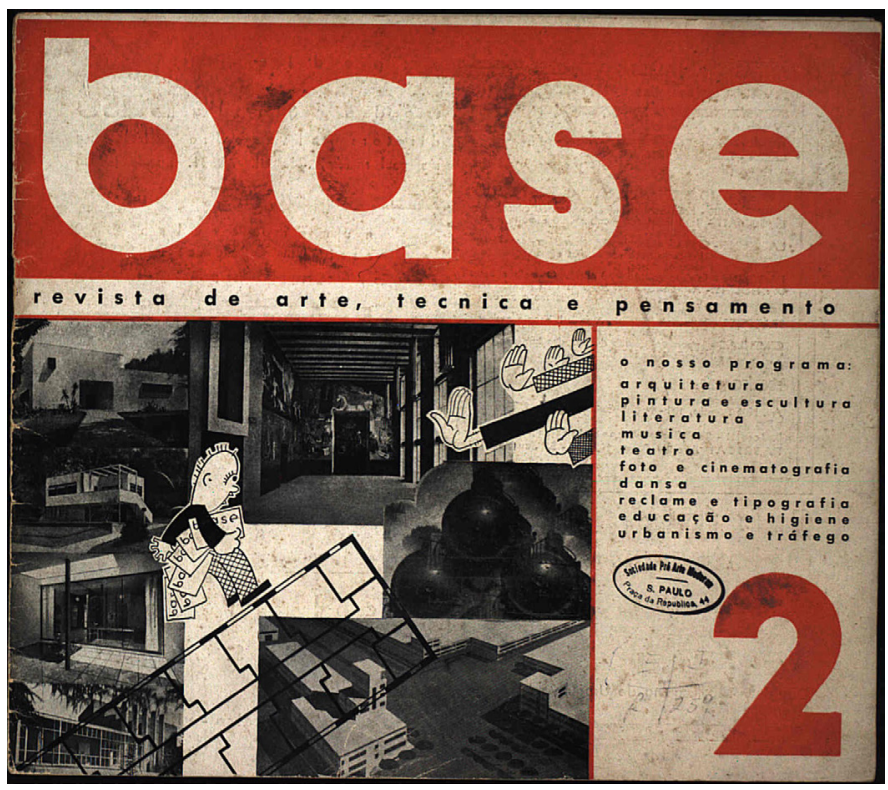

Figura 1 | Capa da Revista Base, n.2, 193.

Fonte: Revista Base, 1931, n.2, Rio de Janeiro. 


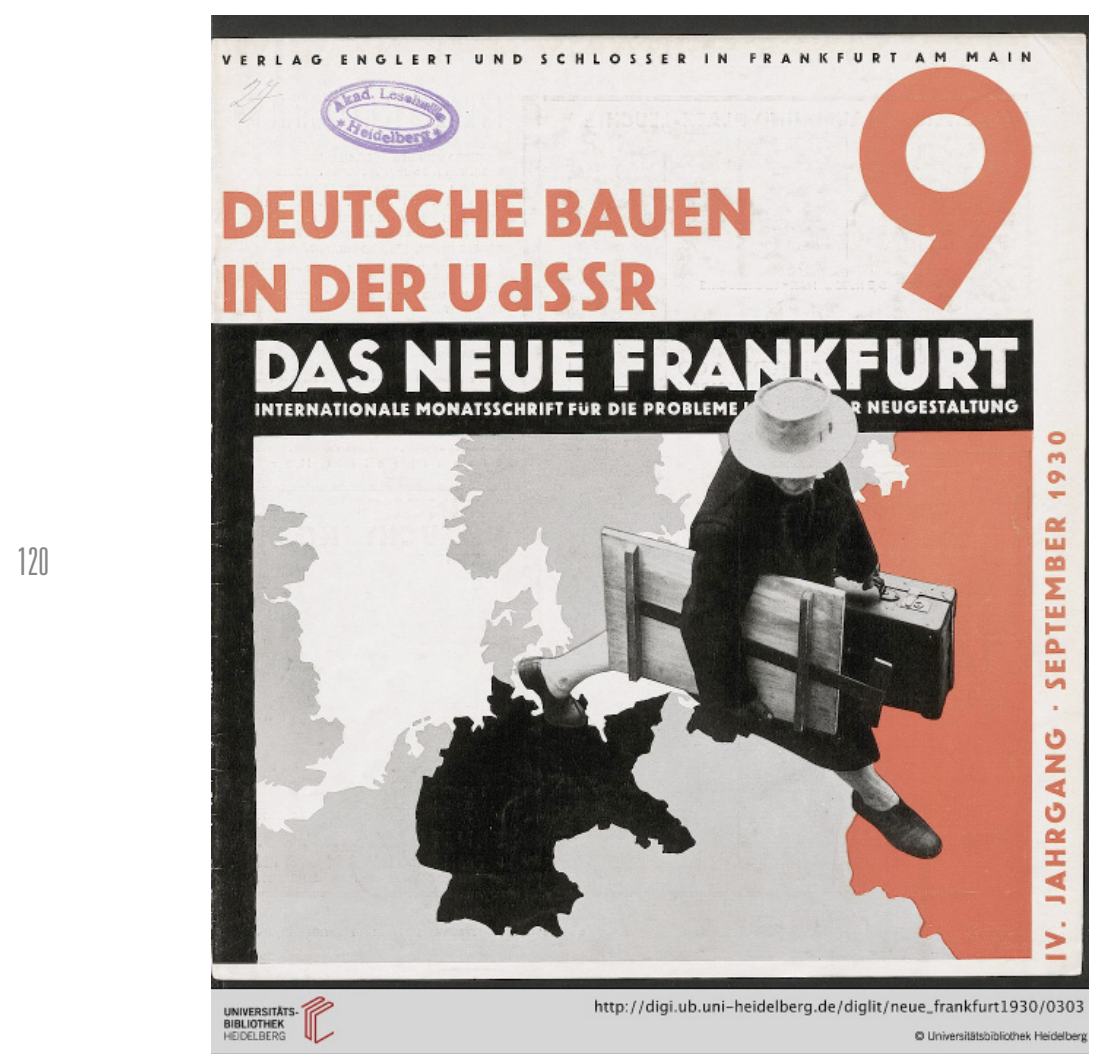

Figura 2 | Capa da Revista Das Neue Frankfurt, n.9, 1930. Fonte: Revista "Das Neue Frankfurt", 1930, In:http://digi.ub.uni-heidelberg.de/diglit/neue_frankfurt 
Sendo Altberg ex-aluno da Bauhaus, não poderia deixar de transparecer na Base a influência da escola. Tendo contato direto com Walter Gropius e Lázlo Moholy-Nagy, os responsáveis pela direção da revista da Bauhaus e das oficinas de tipografia, fica patente na revista Base a influência dos mestres. Duas tipografias apresentadas pela revista da Bauhaus são recorrentes na Base: a tipografia de Josef Albers, e a Sturmblond, de Herbert Bayer, colega de Altberg na Escola (figuras 3 e 4).

\section{WN $\mathbb{N} \mathbb{N} \mathbb{N} \mathbb{N}$

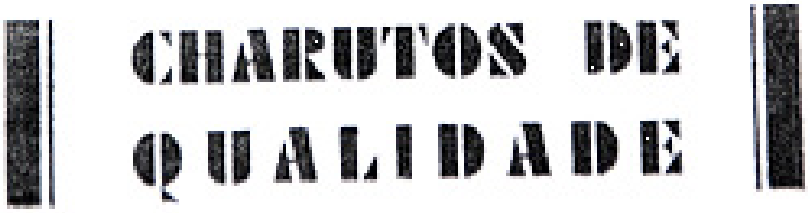

Figura 3 | Tipografia da revista Base, originalmente produzida por Josef Albers. Fonte: Revista "Base", 1931, n.2, Rio de Janeiro. 


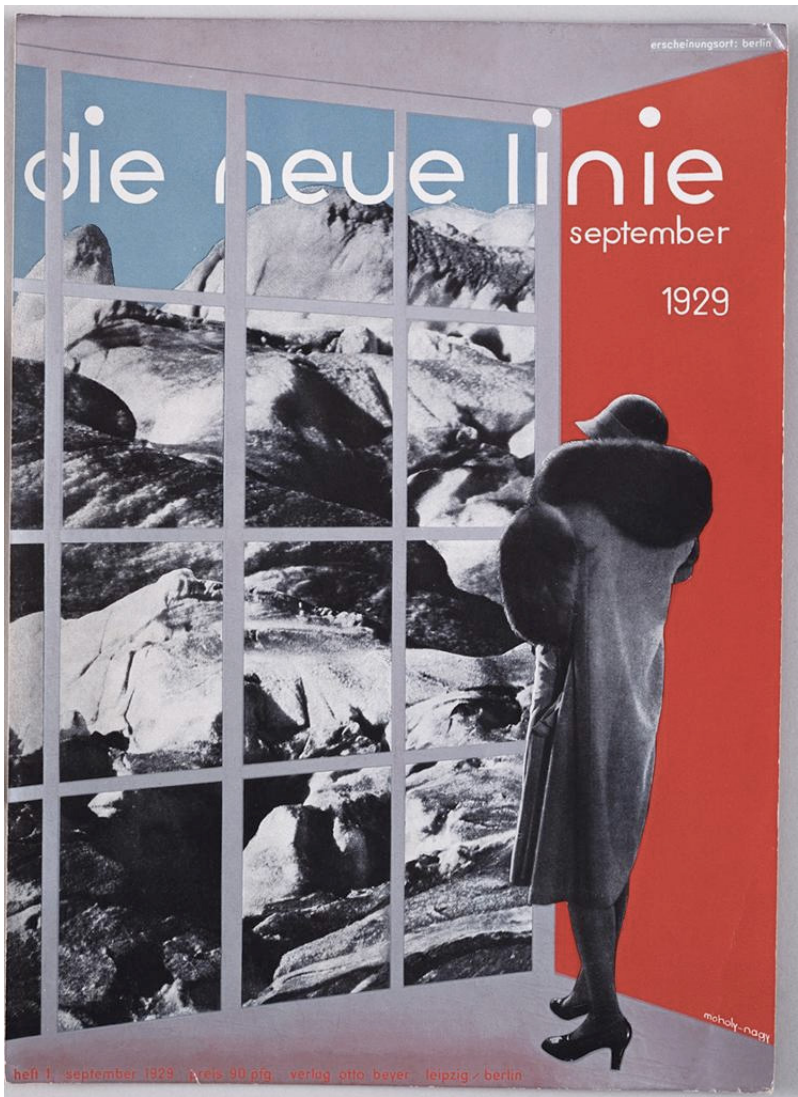

Figura 4 | Capa da revista Die Neue Linie, fonte Sturmblond de Herbert Bayer, utilizada também pela revista Base. Fonte: Die Neue Linie, Setembro de 1929. 
Há também uma clara proximidade entre a dicção arquitetônica de Altberg e a habitação social que se construiu em Frankfurt. No caso do Ginásio Municipal de Ilhéus (figuras 5 e 6), concurso público ganho por Altberg e Lélio Landucci, têm-se estilemas típicos do modernismo alemão, ainda próximo do Expressionismo, que podem ser encontrados em Frankfurt: um longo edifício de três pavimentos, encerrado em sua extremidade por uma solução semicircular, cuja unidade é dada por longas janelas em fita e marquises arredondas. É possível apontar tais elementos como uma influência frankfurtiana direta sobre Altberg, dada a proximidade entre Korn e May.

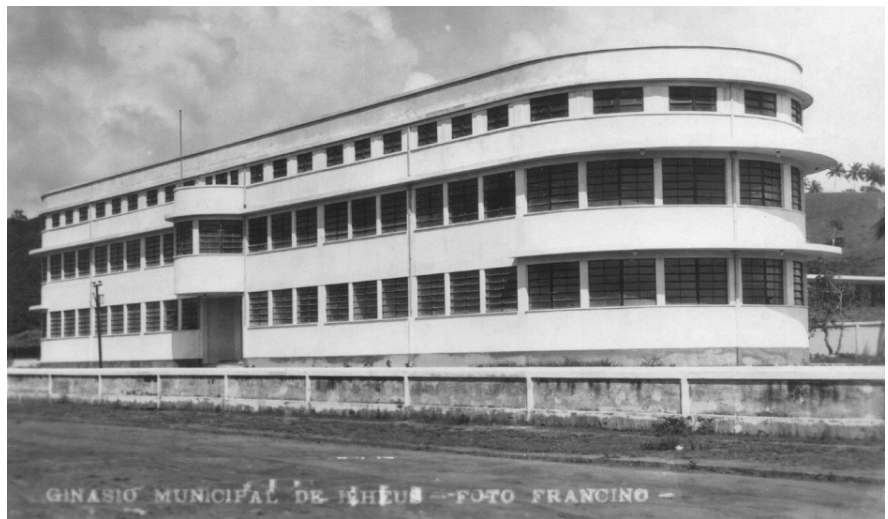

Figura 5 | Ginásio Municipal em Ilhéus, projetado por A. Altberg. Fonte: VIANNA NETO, Liszt. Revista Base: Arte gráfica alemã no modernismo brasileiro. Monografia de graduação defendida pelo Departamento de História, UFMG, 2008. p.161. 


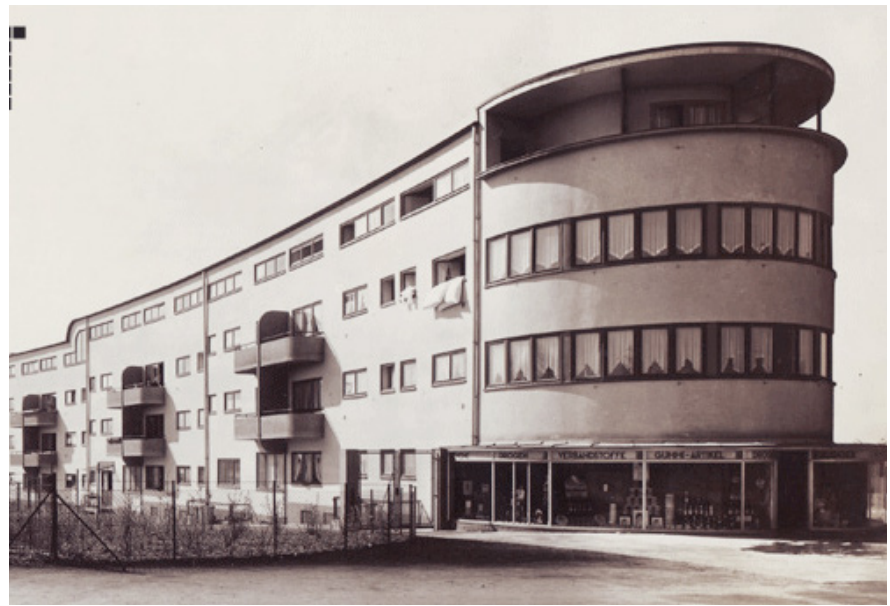

Figura 6 |Bloco de apartamentos em Frankfurt, projetado por E. May. Fonte: Revista Das Neue Frankfurt, 1930, In: http://digi.ub.uni-heidelberg.de/diglit/neue_frankfurt 
Outras proximidades entre Altberg e a Nova Frankfurt podem ser consideradas indiretas, atribuíveis apenas ao contexto modernista alemão que envolvia a ambos. Os projetos de Altberg invariavelmente são de partido prismático e sintético, ausentes de elementos decorativos, ainda que o expressionismo de certas soluções formais garanta tal efeito (figuras 7 e 8).

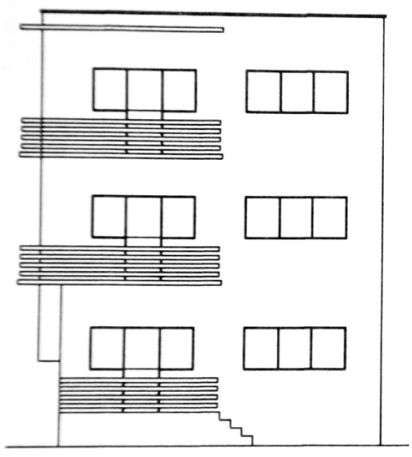

FACHADADARUAJOANAANGÉLICA

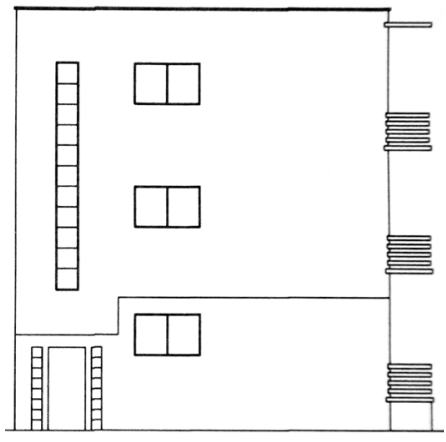

FACHADADARUAALBERTO DE CAMPOS

Figura 7 | Edifício de apartamentos à Rua Joana Angélica, Rio de Janeiro, A. Altberg. Fonte: VIANNA NETO, Liszt. Revista Base: Arte gráfica alemã no modernismo brasileiro. Monografia de graduação defendida pelo Departamento de História, UFMG, 2008. p.167. 


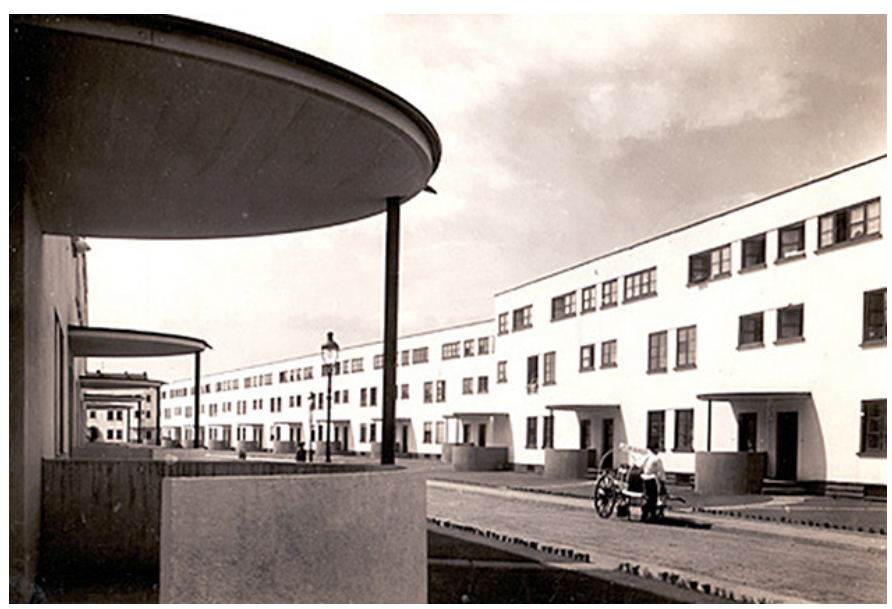

Figura 8 | Bloco de apartamentos em Frankfurt, E. May. Fonte: Revista Das Neue Frankfurt, 1930, In: http://digi.ub.uni-heidelberg.de/diglit/neue_frankfurt 


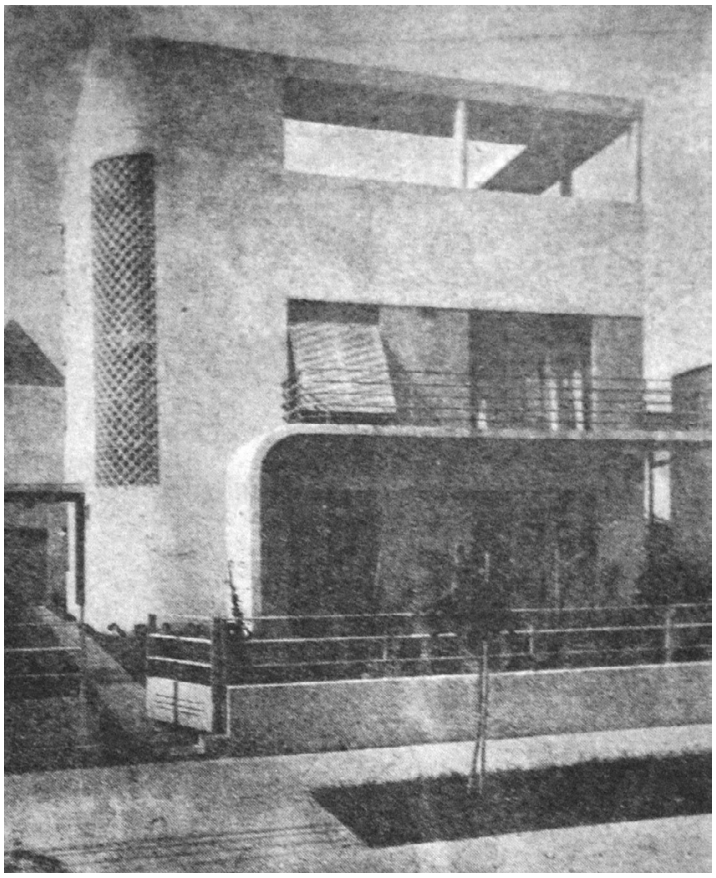

Figura 9 | Fachada Principal da casa Adalberto Vertecz na rua Paul Redfern. Fonte: Revista da Diretoria de Engenharia da Prefeitura do Distrito Federal, no. 13, ano III, 1934, p.139. 


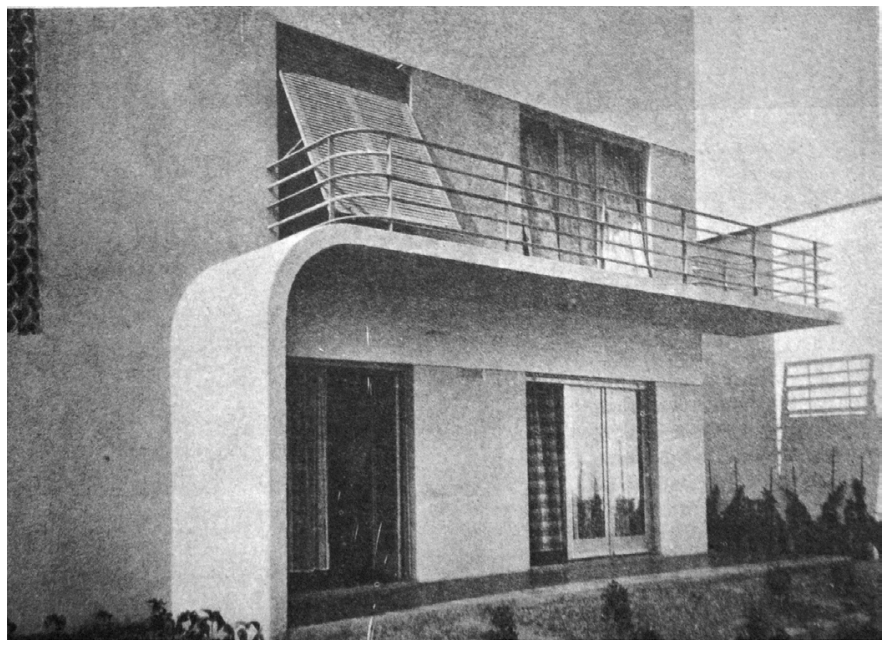

Figura 10 | Detalhe da varanada, casa Vertecz, rua Paul Redfern, projeto de A. Altberg. Fonte: Revista da Diretoria de Engenharia da Prefeitura do Distrito Federal, no. 13, ano III, 1934, p.139. 
Na revista Base, Altberg desenvolve sua crítica arquitetônica estritamente funcionalista. Como Adolf Loos, Altberg ataca o uso do ornamento, a arquitetura de fachadas e a liberdade individual afetada do artista burguês. É implícita nessas notas gerais sua crítica à arquitetura que ele via se desenvolver no Rio de Janeiro, especialmente em Ipanema e Leblon, que se expandiam. Altberg dialoga ainda com uma "estética da máquina", ou com a "máquina de morar", como pensavam os membros do CIAM e o próprio Le Corbusier. Seguindo a cartilha "forma segue a função", na qual a beleza é mero subproduto do arranjo espacial, Altberg defende em seus artigos da Base uma arquitetura antiformalista, que deve servir à pulsação e aos processos vitais: "Hoje em dia o arquiteto, de acordo com a essência da arquitetura moderna, tornou-se mais engenheiro do que artista. Alegra-o tudo quanto é claro e sincero. Construir significa plasmar processos vitais"11. A perspectiva racionalista de Altberg é corroborada por Mário de Andrade, em carta de abertura à revista Base, na qual trata da razão e da ciência, em favor da arte, em consonância com a vida: "a arte está em todos os cantos e penetra todos aspectos da vida".

Ponderando a influência das experiências de Korn, May e Meyer na União Soviética, extrapolar muito além dos limites que foi imposto ao longo deste artigo seria forçoso: o 
caráter experimental de Magnitogorski era fundamentalmente urbanístico. Altberg, no entanto, nunca teve qualquer envolvimento com o urbanismo no Brasil. É verdade que todo o evento da Exposição de Arquitetura Proletária de Berlim se versava sobre a cidade e o urbanismo, mas nada disso veio com Altberg para o Brasil. Devido às dificuldades econômicas, advindas da condição de exilado judeu, imigrado na década do Estado Novo, Altberg foi impelido ao autofinanciamento de seus projetos de pequenos prédios de apartamentos visando à renda dos aluguéis sendo projetos de urbanização algo complemente fora de sua realidade econômica. Apesar de seu ideário político, e da influência de Korn em se pensar a cidade, a vocação de Altberg era a Arquitetura. Altberg até procurou meios de se reaproximar de seus velhos mestres do CIAM, se propondo a representar os Congressos na América Latina. Contudo, Warchavchik já havia sido apontado por Giedion, e a negativa do CIAM chegaria a Altberg em uma carta de Walter Gropius.

Mesmo que tivesse sua carteira profissional no Brasil, as grandes reformas urbanas do Rio de Janeiro eram no mais das vezes inviáveis, sendo executadas parcialmente, pervertendo completamente o projeto inicial. Mesmo projetos de renovação urbana de grande escala eram raramente executados em sua totalidade. É o caso do Plano Agache, no qual Arnaldo Gladosch, cujo escritório Altberg frequen- 
tou por brevíssimo período, colaborou. Mesmo assim, seria descabido pensar que a aplicação de preceitos urbanísticos soviéticos tivesse qualquer respaldo do campo do urbanismo nacional, ainda em formação e voltado a conceitos urbanos do século XIX, como city beautiful, garden city, e principalmente o higienismo haussmaniano.

Embora a revista Base, os projetos habitacionais e a crítica arquitetônica de Altberg transpareçam sua filiação a uma matriz arquitetônica berlinense, desenvolvida a partir de experiências na União Soviética, ainda cabe o questionamento: Por que não se pode localizar uma influência da vanguarda soviética na história do modernismo brasileiro? A resposta passa necessariamente pela experiência de Altberg no exílio. No Brasil, a atuação política de Altberg foi completamente coibida e cerceada.

Apesar de Altberg nunca ter sido assediado gravemente pelo DOPS ou pela imigração, muitos judeus-comunistas foram presos na década de 1930. Os organizadores da Brazcor, ligada ao PCB, no Rio de Janeiro, em sua maioria judeus, foram todos presos. Havia leis, decretos e circulares secretas que corriam os órgãos consulares e portuários, restringindo explicitamente a entrada e circulação de judeus no Brasil - sob argumentos racistas, certamente, e também anticomunistas. 
Além da perseguição do DEOPS, os arquitetos imigrados penaram gravemente ao buscar ter suas carteiras profissionais reconhecidas - a revalidação se tornou necessária a partir de 1933. Além de impossibilitados de trabalhar, os estrangeiros imigrados tiveram seus direitos civis básicos gravemente tolhidos durante o Estado Novo. A Constituição de 1937, chamada "Polaca", limitou o direito de livre circulação dos estrangeiros no país, vetando-lhes a atividade profissional sem visto permanente, o acesso aos cargos públicos e o direito de ser proprietário, acionista ou diretor de empresas jornalísticas.

Além da política imigratória claramente antissemita e da ação policial do DEOPS, a declaração de guerra aos países do Eixo em 1942 fez irromper um surto de antigermanismo no Brasil. Mais grave foram as prisões arbitrárias e sem julgamento, que resultavam no encarceramento em campos de prisioneiros. Houve também a depredação de bibliotecas, lojas e casas de alemães, com a vista grossa das autoridades. Evidentemente tal depredação incluiu imigrantes judeus alemães que, além de serem vítimas do antissemitismo nazista, foram vítimas do antigermanismo varguista. $\mathrm{Na}$ Capital Federal, o Estado empastelou jornais da comunidade alemã e expropriou o Hospital Alemão, assim como a sede do Club Germania - entregue à União Nacional dos Estudantes e transformado em um "quartel-general da luta contra a 'quinta coluna'.". 
Com o fim da Segunda Guerra Mundial e do Estado Novo em 1945, foi promulgada a constituição de 1946, garantido novamente os direitos iguais entre brasileiros e estrangeiros. Contudo, os anos formativos do modernismo brasileiro já haviam passado, e a Escola Carioca havia conquistado sua hegemonia sobre o campo arquitetônico modernista, graças ao financiamento estatal por meio do ministério de Gustavo Capanema. Dessa forma, o espectro do comunismo foi sobrepujado pelo espectro do autoritarismo da Era Vargas.

\section{Referência}

ALTBERG, Alexander. Memórias. Não publicado.

AMARAL, Aracy A. Artes plásticas na semana de 22. São Paulo;

Editora 34, 2001.

AZEVEDO, Paulo Ormindo de. Alexander S. Buddeüs: a passagem do cometa pela Bahia. Arquitextos nº 081.01 São Paulo, Portal Vitruvius, jan. 2008.

BAUHAUS ZEITSCHRIFT, 1926-1931.

BOMENY, Helena. Constelação Capanema: intelectuais e políticas. Rio de Janeiro: Univ. São Francisco: Ed. FGV, 2001.

CADERNOS DETIPOGRAFIA. No.4, 2007.

CANEZ, Ana Paula. Arnaldo Gladosch: $O$ edifício e a metrópole. Porto Alegre: Ed. UniRitter, 2008.

CATÁLOGO DA EXPOSIÇÃO DE ARQUITETURA PROLETÁRIA. Berlim: 1931.

COSTA, Lúcio. Arquitetura brasileira. Rio de Janeiro: Série "Os

Cadernos de Cultura", Serviço de Documentação do Ministério da 
Educação e Saúde, 1952.

. Imprévu et importance de la contribuition des architectes

Brésiliens, in L'Architecture D’Aujourd'hui, n. 42-43, agosto, 1952, p. 7.

Lucio Costa: Registro de uma vivência. São Paulo, Empresa das Artes, 1995.

DROSTE, Magdalena. Bauhaus. Taschen, 2006.

FAUSTO, Boris (org.). Fazer a América: a imigração em massa para a America Latina. São Paulo: EDUSP, 2000.

FERRAZ, Geraldo. Warchavchik e a introdução da nova arquitetura no Brasil: 1925 a 1940. Museu de arte de São Paulo, 1965.

GAY, Peter. A cultura de Weimar. Rio de Janeiro: Editora Paz e Terra, 1978.

GORELIK, Adrian; LIERNUR, Jorge Francisco. La sombra de la vanguardia: Hannes Meyer en Mexico, 1938-1949. Buenos Aires: Proyecto, 1993.

HAYS, K. Michael. Modernism and the posthumanist subject: the architecture of Hannes Meyer and Ludwig Hilberseimer. Cambridge, Mass.: MIT Press, c1992.

HOFFMANN, Hubert. Erinnerungen an Arthur Korn. Revista Der Aufbau.

KLIEMANN, Helga. Die Novembergruppe. Berlin: Gebr. Mann, 1969.

HERF, Jeffrey. O modernismo reacionário: tecnologia, cultura e política em Weimar e no Terceiro Reich. São Paulo: Ensaio; Campinas, SP: Editora Unicamp, 1993, p.181.

JUNKER, Wolfgang (org.). Architektur der DDR. Berlin: 1981.

KOPP, Anatole. Quando o moderno não era um estilo e sim uma causa. São Paulo SP, Nobel, 1990.

KOPP, Anatole. Constructivist Architecture in the USSR. Academy Editions, 1985.

KORN, Arthur. Glas im Bau und als Gebrauchsgegenstand. Berlim, 1929. 
History builds the town. Londres, 1953.

; FRY, Maxwell; SHARP, Dennis. The M.A.R.S. Plan for Lon-

don. Perspecta, Vol. 13, 1971.

LACOMBE, Marcelo S. Masset. Modernismo e nacionalismo: o jogo das nacionalidades no intercâmbio entre Brasil e Alemanha. Tese de pós-doutorado defendida pela Fapesp-Unicamp.

LIRA, José Tavares Correia de. Warchavchik: fraturas da vanguarda. São Paulo: Cosac \& Naify, 2011.

MATTOS, Cláudia V. Lasar Segall. São Paulo: Editora da Universidade de São Paulo, 1997.

MICELI, Sergio. Nacional estrangeiro. São Paulo: Companhia das Letras, 2003.

Imagens negociadas: retratos da elite brasileira (1920-40). São Paulo: Cia. das Letras, 1996.

MINDLIN, Henrique Ephim. Modern architecture in Brazil. Rio de Janeiro e Amsterdam: Colibris Editora, 1956.

MOREIRA, Pedro. A cultura arquitetônica dos países de língua alemã e seus reflexos no desenvolvimento da Arquitetura Moderna no Brasil - 1880-1945 In Martius-Staden-Jahrbuch. N.52, 2005.

Alexandre Altberg e a Arquitetura Nova no Rio de Janeiro. Arquitextos $n^{\circ}$ 058. São Paulo, Portal Vitruvius, mar. 2005. <http:// vitruvius.es/revistas/read/arquitextos/05.058/484>

MOTTA, Rodrigo Patto Sá. Em guarda contra o 'perigo vermelho': o anticomunismo no Brasil (1917-1964). São Paulo: Perspectiva: FAPESP, 2002.

NICOLAl, Bernd (Org.). Architektur und Exil, Kulturtransfer und architektonische Emigration 1930 bis 1950. Porta Alba Verlag, Trier, 2003.

NOBRE, Ana Luísa. Carmen Portinho. Ed. Relume Dumará, Rio de Janeiro, 1999.

PORTINHO, Carmen. Por toda a minha vida. Rio de Janeiro:

Ed.UERJ, 2000.

REVISTA BASE. Nos.1-3. Rio de Janeiro, 1933-34. 
RICHARD, Lionel. A República de Weimar. São Paulo: Companhia das Letras, 1988.

SCHWARTZMAN, Simon; BOMENY, Helena Maria Bousquet; COSTA, Vanda Maria Ribeiro. Tempos de Capanema. Rio de Janeiro: Editora Paz e Terra/ FGV, 2000.

SCHWARTZ, Jorge. Vanguardas latino-americanas: Polêmicas, manifestos e textos críticos. São Paulo: Editora da Universidade de São Paulo: Iluminuras: FAPESP, 1995.

SEGAWA, Hugo. Arquiteturas no Brasil 1900-1990. São Paulo: Edusp, 1998.

VIANNA NETO, Liszt. Revista Base: arte gráfica alemã no modernismo brasileiro. Monografia de graduação defendida pelo Departamento de História, UFMG, 2008.

WARCHAVCHIK, Gregori. Arquitetura do século XX e outros escritos. Cosac Naify, 2006.

WEIMER, Günter. Arquitetura modernista em Porto Alegre entre 1930 e 1945. Unidade Editorial, 1998.

XAVIER, Alberto. Arquitetura moderna brasileira: depoimento de uma geração. São Paulo: 1987.

ZEESE, Andreas. Die vergessene Moderne: Arthur Korn - Architekt, Urbanist, Lehrer (1891-1978). Leben und Werk eines jüdischen Avantgardisten in Berlin und London. Tese defendida pela Universidade de Viena, 2010.

FEZER, Jesko, HILLER, Christian, NEHMER, Alexandra, OSWALT, Philip. Kollektiv für sozialistisches Bauen: Proletarische Bauausstellung, Verlag: Spector Books, zusammen mit dem Haus der Kulturen der Welt, 2015

VIANNA NETO. Liszt. Modernismo, socialismo e exílio: Alexander Altberg no Rio de Janeiro da Era Vargas (1930-1945). Dissertação defendida pelo Núcleo de Pós-Graduação em Arquitetura e Urbanismo, UFMG, 2014. 